- (1991b) Professional Advice for Purchasers - a DHA Project Discussion Paper. London: NHS Management Executive.

Royal Australian \& New Zealand College of PsyCHIATRISTs (1982-1985) The Qualify Assurance Project. Royal Australian \& New Zealand Journal of Psychiatry, $16,25-33,153-158 ; 17,129-146 ; 18,19-38 ; 19,138-151$, 240-253, 397-407. Sydney: Royal Australian \& New Zealand College of Psychiatrists.
Royal College of Psychiatrists (1992) Mental Health of the Nation-The Contribution of Psychiatry. Council Report CR 16. London: Royal College of Psychiatrists.

- \& Faculty of Public Health Medicine Report of Joint Working Group on the Purchasing of Psychiatric Care. In preparation. London: Royal College of Psychiatrists/Faculty of Public Health Medicine.

\title{
Confidential Enquiry into Homicides and Suicides by Mentally III People
}

A Confidential Enquiry has been set up to review cases of homicides and suicides by mentally ill people. It is appreciated that those looking after people with psychiatric illnesses have always been alert to the need to protect those in their care. However, the objective of the enquiry is to discover whether some of these distressing deaths might have been prevented by different approaches to clinical management or by different provision of care.

As Director of the Enquiry, I have been greatly encouraged by the positive support which I have already received from those with whom I have discussed our plans and I am now keen to make readers of the Psychiatric Bulletin aware of our intentions.

Cases will be identified through various channels, and I shall then be writing to the psychiatrist most likely to have knowledge of the circumstances surrounding the illness or death of the notified individual. I shall ask them to complete a questionnaire and to give me their frank opinion as to whether in retrospect they consider that alternative strategies of specific treatment or of more general management might have reduced the likelihood of death.

I want to emphasise that the responses which I receive will be treated with the utmost confidentiality and that complete anonymity of patient and of respondent will be ensured. With this assurance I am hopeful that anyone receiving a letter from me will recognise that their individual response, when associated with many other responses from around the country, will allow us to make some useful recommendations about the care of those who are at risk of harming themselves or others.

W. D. BoYD Director

Confidential Enquiry into

Homicides \& Suicides by Mentally Ill People 